\title{
A numerical model to evaluate the flow distribution in a large solar collector field
}

\author{
Bava, Federico; Dragsted, Janne; Furbo, Simon
}

Published in:

Solar Energy

Link to article, DOI:

10.1016/j.solener.2016.12.029

Publication date:

2017

Document Version

Peer reviewed version

Link back to DTU Orbit

Citation (APA):

Bava, F., Dragsted, J., \& Furbo, S. (2017). A numerical model to evaluate the flow distribution in a large solar collector field. Solar Energy, 143, 31-42. https://doi.org/10.1016/j.solener.2016.12.029

\section{General rights}

Copyright and moral rights for the publications made accessible in the public portal are retained by the authors and/or other copyright owners and it is a condition of accessing publications that users recognise and abide by the legal requirements associated with these rights.

- Users may download and print one copy of any publication from the public portal for the purpose of private study or research.

- You may not further distribute the material or use it for any profit-making activity or commercial gain

- You may freely distribute the URL identifying the publication in the public portal

If you believe that this document breaches copyright please contact us providing details, and we will remove access to the work immediately and investigate your claim 
1 A numerical model to evaluate the flow distribution in a large solar collector

2 field

\section{Federico Bava*, Janne Dragsted and Simon Furbo}

4 DTU Civil Engineering, Technical University of Denmark, Brovej, Building 118, 2800 Kgs. Lyngby 5 (Denmark)

$6 \quad *$ Tel.: +45 45251700, Email: febav@byg.dtu.dk

\section{Abstract}

8 This study presents a numerical model to evaluate the flow distribution in a large solar collector field, with 9 solar collectors connected both in series and in parallel. The boundary conditions of the systems, such as 10 flow rate, temperature, fluid type and layout of the collector field can be easily changed in the model. The 11 model was developed in Matlab and the calculated pressure drop and flow distribution were compared with 12 measurements from a solar collector field. A good agreement between model and measurements was found. 13 The model was then used to study the flow distribution in different conditions. Balancing valves proved to be 14 an effective way to achieve uniform flow distribution also in conditions different from those for which the 15 valves were regulated. For small solar collector fields with limited number of collector rows connected in 16 parallel, balancing valves are not strictly necessary if the pressure drop across the collector rows is much 17 higher than the pressure drop along the longest distribution pipe.

18 Keywords: solar collector, solar collector field, flow balancing, flow distribution, parallel connection.

\section{1. Introduction}

\subsection{Background}

An increasing number of large solar collector fields have been built in Europe in the last years. The main market for this technology has been Denmark, with 77\% of the total collector area installed in European large scale solar heating plants at the end of 2015 (Mauthner et al., 2016). This development has been driven by some specific factors, such as high taxation on fossil fuels and widespread use of district heating (DH), to which large collector areas can be connected (Furbo et al., 2015). At the end of 2015, Denmark had more than $800,000 \mathrm{~m}^{2}$ of solar collector fields, and more plants are expected to be installed in the next years (Figure 1). Also the size of the collector fields has been increasing. In 2015 the current largest collector field was installed in Vojens, with a collector area of 70,000 $\mathrm{m}^{2}$ (Mauthner et al., 2016). In 2016 a 150,000 $\mathrm{m}^{2}$ collector field is expected to be completed in Silkeborg (EnergySupply, 2016). 


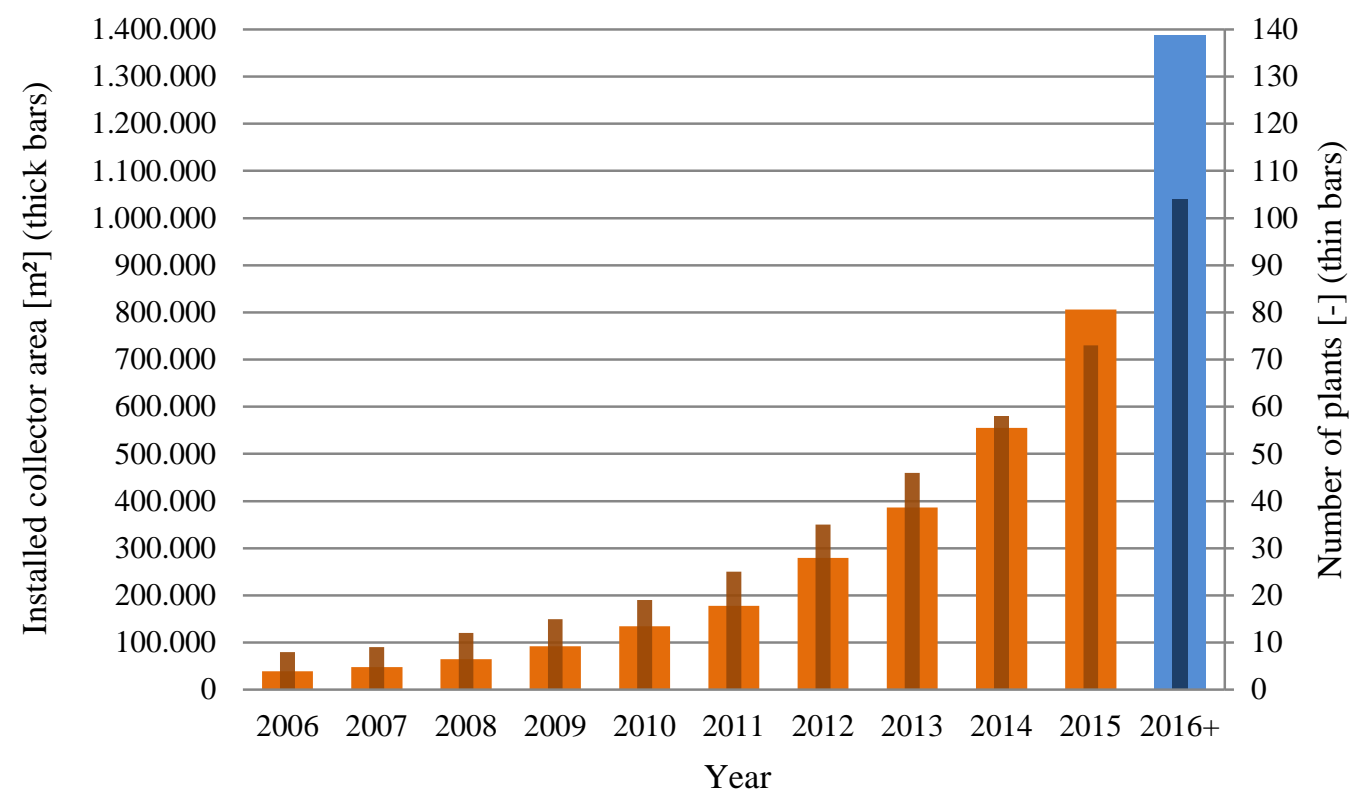

Figure 1: Historical development of solar collector fields for DH applications in Denmark: installed collector area and number of operating (orange) and upcoming (blue) plants at the end of 2015 (Trier, 2016).

The larger the solar collector field and the number of collector rows, the higher the risk of non-uniform flow distribution from one row to another and decreased thermal performance. In fact, identical collector rows supplied with different flow rates reach different outlet temperatures. Mixing flows at different temperatures causes a lower temperature rise across the collector field compared to the case with uniform flow distribution and identical outlet temperatures. If different rows have a different number of collectors (and different aperture areas), these should be supplied by different flow rates, proportional to the collector row area, resulting in the same outlet temperature for all rows.

\subsection{Literature review}

Flow distribution in solar thermal systems has been the topic of many investigations, both at collector level and array level. The negative effect of the flow maldistribution on the thermal performance of a single collector with parallel channels was investigated by Chiou (1982). He presents a method to determine how much the collector efficiency is penalized by the flow maldistribution. Wang and Wu (1990) developed a numerical model to predict the flow distribution in collector arrays with vertical pipes, both in U-type and Ztype configuration. Compared to the Z-type configuration, the U-type presents a higher maldistribution, with the flow rates in the absorber pipes decreasing monotonically with the distance from the array inlet. The same trend is found by Jones and Lior (1994), who considered a single collector with vertical pipes, instead of an entire array. Weitbrecht et al. (2002) present both an experimental and analytical study on the flow distribution in a Z-type collector in isothermal conditions, verifying the results from Wang and Wu (1990) and Jones and Lior (1994). They conclude that a more uniform flow distribution is achieved when the pressure losses in the absorber pipes are much higher than in the manifolds. Fan et al. (2007) studied the flow and temperature distribution in a solar collector for large collector fields applications. Calculations with a CFD model and experimental measurements are compared. The authors conclude that the flow distribution is determined by friction (and hence buoyancy can be neglected), if the velocity in the collector pipes is high compared to the temperature rise across the collector. Bava and Furbo (2015) propose a numerical model to evaluate the pressure drop and flow distribution in a collector with horizontal U-connected pipes. Based on the findings of Fan et al. (2007), the authors argue that in large collector fields for DH applications the relation between the fluid velocity in the absorber pipes and the temperature rise across the collector is such that buoyancy can be neglected. The model was validated against measurements carried out on a collector for solar assisted DH plants.

Uniform flow distribution is of great importance also for the efficient operation of the entire collector field, but it is often overlooked (Dorantes et al., 2014). Ideally, the layout of a collector array should keep the pipe lengths as short and the flow distribution as uniform as possible. Shorter pipe lengths entail lower material 
and installation costs, lower thermal losses from the distribution lines, reduced pressure drop and consequently lower pumping power. Since reduction in pipe length and uniform flow distribution cannot be optimized simultaneously, a compromise between the two needs to be found. Rohde and Knoll (1976) investigate different hydraulic solutions for minimizing the flow maldistribution in a collector field of 12 collector rows connected in parallel. These solutions include various size manifolds, orifices and balancing valves. The last two are proposed as the best solutions, both in terms of performance and cost. It is noted that a configuration of valve settings maintains the desired flow distribution only at a certain flow rate. Finally, laminar flow produces less uniform flow distribution than turbulent flow. Also Knabl et al. (2014) present different solutions to achieve uniform flow distribution. A solution consists of maintaining a constant pipe diameter in the supply and return pipe. An example is represented by the first large collector fields built in Sweden, such as Falkenberg (1989) and Nykvarn II (1991). Another possibility is to adopt a Z-configuration (or reverse return). Though, both these solutions entail higher costs due to the additional material. Balancing valves can be installed in each row, but these increase the investment cost, installation time and maintenance (in case of defective valves). Installing pipes with different diameters within each collector row is a cheaper solution, but must be calculated in advance exactly, as a later adjustment would be very expensive.

\subsection{Solar collector fields for $\mathrm{DH}$ applications}

In Denmark the majority of large collector fields are installed next to a heating plant supplying a DH network. The inlet temperature to the collector field is determined by the return temperature from the $\mathrm{DH}$ network. Typical return temperatures are in the interval 35-45 ${ }^{\circ} \mathrm{C}$ (Windeleff and Nielsen, 2014). The control strategy of the collector field aims at reaching a constant outlet temperature, by continuously regulating the total flow rate based on the solar irradiance (Heller, 2000). The desired outlet temperature is the DH supply temperature. Typical supply temperatures are in the interval $70-85{ }^{\circ} \mathrm{C}$ (Windeleff and Nielsen, 2014). The temperature drop across the heat exchanger should be considered. When sufficiently high temperatures cannot be reached, for example in periods with low solar irradiance, the additional energy is provided by an auxiliary energy source.

Most of the Danish collector fields are made of 12-14 $\mathrm{m}^{2}$ flat plate harp collectors (Windeleff and Nielsen, 2014). The diameter of the supply and return pipes to and from the collectors is progressively decreased as the fluid is diverted to the collector rows. A uniform flow distribution across the collector field is achieved by installing balancing valves at the inlet of each collector row. Unlike orifices, the setting of these valves can be changed if needed, so providing a higher flexibility. Additionally, if coupled with an on/off valve at the row outlet, balancing valves can be used for maintenance purposes. For example, in case of leakage in a row, this can be isolated, while the rest of the collector field continues its normal operation. The setting of the valves is usually chosen in such a way that the desired flow distribution is achieved in nominal operating conditions, i.e. high solar irradiance, high flow rate, nominal inlet and outlet temperatures. As found by Rohde and Knoll (1976), these valve settings provide a perfectly uniform flow distribution only in a specific operating condition, while deviations can be expected in other conditions.

Being able to evaluate these deviations is of great interest, as it allows understanding how the collector field performance is affected by off-design conditions. Additionally, it is of particular importance with respect to critical conditions such as incipient stagnation and anti-freezing mode. A collector row supplied with a lower flow rate is more likely to experience stagnation or freezing. This represents a risk for the entire system and penalizes the overall performance. If one row is not supplied by the proper flow rate and so reaches too high temperatures, this may trigger an alarm signal, which interrupts the normal operation of the collector field with consequent loss of useful energy production. On the other hand, when the system switches to antifreezing mode, the solar collector fluid (usually 30-40\% propylene glycol/water mixture (Windeleff and Nielsen, 2014)) is circulated across the collector field. Rows supplied with lower flow rates are more likely to incur into freezing in case of extended cold periods.

The aim of this study was to develop a numerical model for calculating the flow distribution across a large collector field. The reliability of the model was verified by comparing its results against experimental measurements. Different scenarios were treated to analyze how different operating conditions, layouts and design choices can affect the flow distribution. The Matlab source code of the model is publicly available online (Bava, 2016) and can be edited to treat different configurations. 


\subsection{Numerical model}

\subsubsection{Pressure drop correlations}

To evaluate the flow distribution in a parallel hydraulic system, the relation between flow rate and pressure drop across each component needs to be known. In a parallel hydraulic system, the fluid flow distributes so that the pressure drop along each hydraulic path is the same. Consequently, hydraulic paths characterized by higher hydraulic resistance will receive lower flow rates. As the relation between pressure drop and fluid velocity is neither generally linear nor constant, the flow distribution across a parallel system changes depending on the total flow rate. Also variations of the fluid viscosity and density can affect the flow distribution.

126 In a solar collector field it is possible to distinguish three main types of hydraulic components: solar collectors, pipes (distribution pipes and row inlet/outlet) and fittings (bends, tee junctions, valves, etc.).

The pressure drop characteristic of a solar collector can be difficult to find in technical datasheets, as it is not compulsory for the manufacturer to provide (ISO, 2014). Even if provided, this relation is usually given for a specific fluid and temperature. So, care should be taken when using other fluids and/or temperatures.

In this study the collector pressure drop was calculated using the model proposed by Bava and Furbo (2016). The modeled collector was a HTHEATStore 35/08 from the company Arcon-Sunmark A/S (SP, 2015). This is a flat plate harp collector with U-type configuration and an aperture area of $12.60 \mathrm{~m}^{2}$. Its 18 absorber pipes are $5.80 \mathrm{~m}$ long, have an inner diameter of $7.3 \mathrm{~mm}$ and an intermediate spacing of $122 \mathrm{~mm}$. The manifolds have an inner diameter of $32.9 \mathrm{~mm}$. The calculated pressure drop is shown in Figure 2 as function of temperature and flow rate for a $35 \%$ propylene glycol/water mixture. The thermophysical properties of the fluid were evaluated through (Eq. 8) and (Eq. 9).

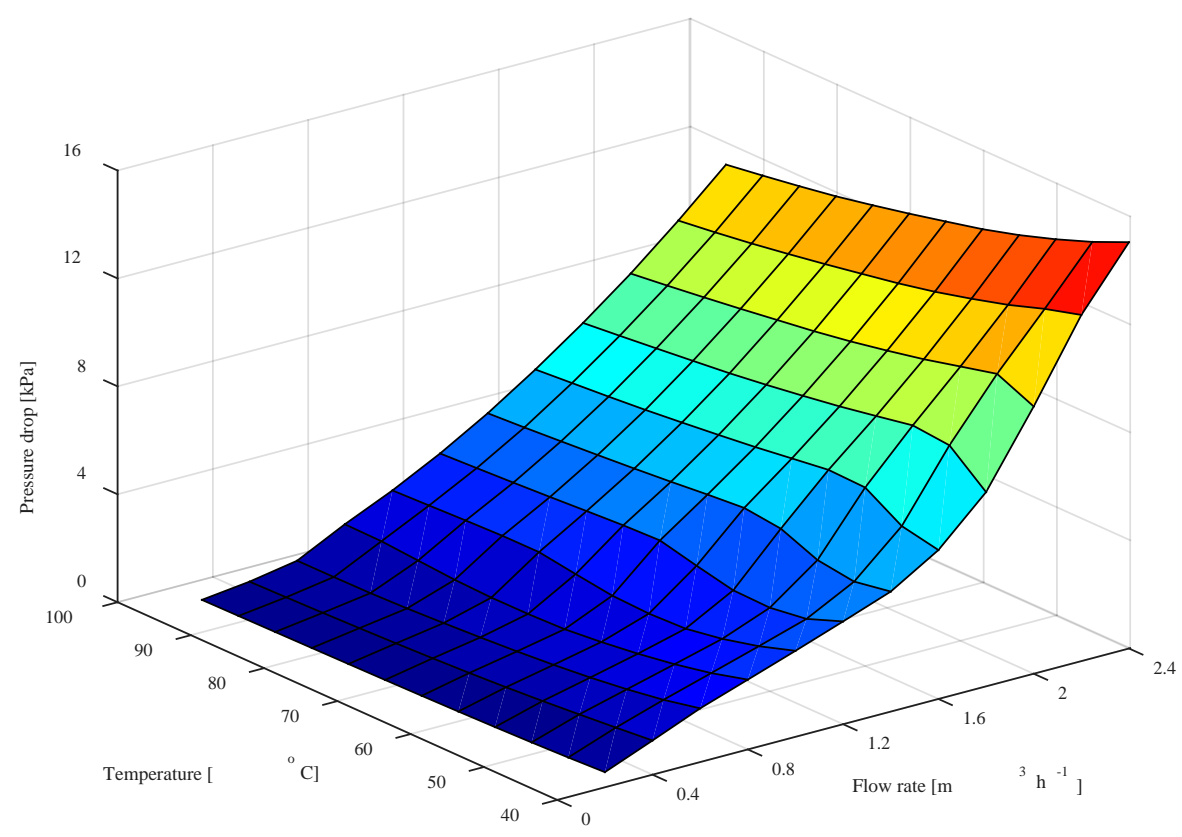

Figure 2: Pressure drop of a HTHEATstore 35/08 collector as function of temperature and flow rate for 35\% propylene glycol/water mixture.

141 The friction loss along a straight pipe of constant cross section can be calculated by the Darcy-Weisbach 142 equation:

144 where $\Delta p$ is the pressure drop [Pa], 

$\rho$ is the density of the fluid $\left[\mathrm{kg} \mathrm{m}^{-3}\right]$, $w$ is the mean fluid velocity $\left[\mathrm{m} \mathrm{s}^{-1}\right]$.

In case of Reynolds numbers (Re) lower than 2300, laminar flow regime was assumed (Holman, 2002) and the Darcy friction factor was calculated through the Hagen-Poiseuille law (Eq. 2):

$$
\lambda=64 / R e
$$

For $R e>4000$, the flow was assumed turbulent (Holman, 2002) and the friction factor was calculated through the Haaland (1983) correlation for rough pipes (Eq. 3), as the distribution pipes were made of steel with roughness $\varepsilon=10^{-4} \mathrm{~m}$ (Li and Svendsen, 2013).

$$
\lambda^{-1 / 2}=-1.8 \log _{10}\left\{\left[\varepsilon /\left(3.7 D_{h}\right)^{1.11}+6.9 / R e\right]\right\}
$$

where $\varepsilon$ is the absolute surface roughness of the pipe inner surface [m].

The Haaland correlation is an explicit, and hence faster to solve, formulation of the Colebrook (1939) equation. Beside the mentioned correlations, other correlations were implemented in the model, such as those proposed by Colebrook (1939) for turbulent flow in rough pipes, by Blasius (1913) for turbulent flow in smooth pipes and by Joseph and Yang (2010) for any flow regime in smooth pipes.

162 Following the example of Jones and Lior (1994), the friction factor in the transition region $(2300<R e<4000)$

163 was calculated by linear interpolation between the value obtained from (Eq. 2) for $R e=2300$ and that obtained 164 from (Eq. 3) for $R e=4000$.

165 Regarding local losses in fittings, such as bends, tee junctions, changes of flow section area, etc., correlations 166 from Idelchik (1994) were used. Regarding balancing valves, the relation between flow rate and pressure 167 drop is usually provided by the manufacturer in terms of flow factor $K_{v}$ (Eq. 4):

$$
K_{v}=V \sqrt{\frac{S G}{10^{-5} \Delta p}}
$$

where $\quad V$ is the fluid flow rate $\left[\mathrm{m}^{3} \mathrm{~h}^{-1}\right]$,

$S G$ is the fluid specific gravity [-].

The $K_{v}$ values are given as function of the valve setting and refer to water and fluids with similar viscosity. Deviations from the nominal $K_{v}$ value are expected for other types of fluid and at flow rates significantly smaller than the valve nominal flow rate (IMI Hydronic, 2015a). In these cases, corrections need to be applied. In this study, valves from IMI-Hydronic were used and their $K_{v}$ values in different operating conditions were estimated though the software HySelect (IMI Hydronic, 2014).

\subsubsection{Fluid properties}

Usually propylene glycol/water mixtures are used as solar collector fluid in solar collector fields. For the relevant thermophysical properties of these mixtures, the following correlations were implemented in the model (Conde, 2011).

$$
\begin{aligned}
& \rho=508.4-0.1824 x+965.8 T^{*}+0.2803 x T^{*}-472.2 \cdot\left(T^{*}\right)^{2} \\
& c_{p}=4476+608.6-715.0 T^{*}-1939 x T^{*}+478.7 \cdot\left(T^{*}\right)^{2}
\end{aligned}
$$

$$
\ln \mu=-1.028-0.1003 x-19.94 T^{*}+0.1464 x T^{*}+14.6205 \cdot\left(T^{*}\right)^{2}
$$

where $\quad c_{p}$ is the specific heat of the fluid $\left[\mathrm{J} \mathrm{kg}^{-1} \mathrm{~K}^{-1}\right]$, $\mu$ is dynamic viscosity of the fluid [Pa s], $x$ is the mass concentration of propylene glycol in the mixture [\%], $T^{*}$ is a factor defined as $T^{*}=273.15 /(T+273.15)$, where $T$ is the fluid temperature $\left[{ }^{\circ} \mathrm{C}\right]$. 
187 A large variability of the properties of propylene glycol/water mixtures was found when comparing different sources in literature (Conde, 2011; George and Sastry, 2003; Melinder, 2007; Sun and Teja, 2004; Tsierkezos and Palaiologou, 2009) or product datasheets (DOW, 2008; Skovrup, 2005). In fact, different commercial propylene glycols may contain different amounts and types of additives to prevent corrosion. Additionally, propylene glycol is known to suffer acidic degradation and hence change its composition over time, especially when exposed to high temperatures (Clifton et al., 1985; Rossiter et al., 1985). For these reasons, when performing the model validation, a sample of propylene glycol/water mixture was taken from the specific collector field and its density and viscosity were experimentally determined. For this purpose, an Anton Paar DMA 4100 densimeter and an Anton Paar AMV 200 viscometer were used. The mixture (glycol mass content of $35 \%$ ) was tested at temperatures between $20^{\circ} \mathrm{C}$ to $80^{\circ} \mathrm{C}$ with an intermediate step of $10^{\circ} \mathrm{C}$. The experimental data points were then interpolated with the expressions (Eq. 8) and (Eq. 9). The specific heat was not determined, as it was not needed for the validation.

$$
\rho=1038.3-0.4419 T-1.940 \cdot 10^{-3} T^{-2}
$$

\subsubsection{Matlab implementation}

Using the pressure drop correlations and the fluid properties described in the previous sections, a numerical model was developed in Matlab to compute the flow distribution in a solar collector field. To provide the necessary input data to the model, the layout of the collector field, pressure drop in the collectors, valves and settings, dimensions of distribution pipes and type of fittings must be known. Also the fluid type and operating conditions, such as field flow rate and fluid inlet temperature, need to be inserted. The temperature profile along the collector rows, used to evaluate the fluid properties, can be estimated in two ways. The first possibility is to define an outlet temperature, equal for all collector rows, and a linear temperature profile is assumed along the collector row. For the second possibility, the collector efficiency coefficients and weather conditions, such as solar irradiance on the collector plane and ambient temperature, must be provided instead. The temperature profile across each collector row is then calculated solving the differential equation (Eq. 10), which assumes steady state conditions.

214 where $\dot{m}$ is the mass flow rate $\left[\mathrm{kg} \mathrm{s}^{-1}\right]$,

$$
\dot{m} c_{p} \frac{d T}{d A}=G \eta_{0} K_{\theta}-a_{1} \cdot\left(T-T_{a m b}\right)-a_{2} \cdot\left(T-T_{a m b}\right)^{2}
$$

$A$ is the gross/aperture collector area $\left[\mathrm{m}^{2}\right]$,

$G$ is the hemispherical solar irradiance on the collector plane $\left[\mathrm{W} \mathrm{m}^{-2}\right]$, $a m b$ subscript denotes ambient temperature.

The solution of (Eq. 10) represents the temperature profile along the collector row and is given by (Eq. 11):

$$
T(A)=\frac{d \cdot \tan \left[\frac{1}{2}(K d+A d)\right]-b}{2 a}
$$

where $a$ is parameter defined as $a=-a_{2} / \dot{m} c_{p}$,

$$
b \text { is parameter defined as } b=2 a_{2} T_{a m b}-a_{1} / \dot{m} c_{p} \text {, }
$$


$c$ is parameter defined as $c=G \eta_{0} K_{\theta}+a_{1} T_{a m b}-a_{2} T_{a m b}^{2} / \dot{m} c_{p}$,

$d$ is parameter defined as $d=\sqrt{4 a c-b^{2}}$,

$K$ is the integration constant, defined based on the inlet temperature boundary condition $T_{\text {in }}\left[{ }^{\circ} \mathrm{C}\right]$ as

$$
K=\frac{2}{d} \tan ^{-1}\left(\frac{b+2 a T_{\text {in }}}{d}\right)
$$

230 As can be seen from (Eq. 11), the temperature profile along a collector row is function of its flow rate, so rows supplied lower flow rates reach higher temperatures.

232 Given an initial total flow rate as input, the model assumes that the flow is uniformly distributed across the collector field. To calculate the true flow distribution, the numerical model solves iteratively the set of equations (Eq. 12), which impose both the conservation of mass across the collector field (first line in (Eq. 12)) and the uniformity of pressure drop along the different hydraulic paths (from second line downward):

$$
\left(\begin{array}{cccccc}
1 & 1 & 1 & 1 & 1 & 1 \\
k_{1, j} \cdot \dot{m}_{1, j} & -k_{2, j} \cdot \dot{m}_{2, j} & 0 & 0 & 0 & 0 \\
0 & k_{2, j} \cdot \dot{m}_{2, j} & -k_{3, j} \cdot \dot{m}_{3, j} & 0 & 0 & 0 \\
\vdots & \vdots & \vdots & \vdots & \vdots & \vdots \\
0 & 0 & 0 & 0 & k_{N-1, j} \cdot \dot{m}_{N-1, j} & -k_{N, j} \cdot \dot{m}_{N, j}
\end{array}\right)\left(\begin{array}{c}
\dot{m}_{1, j+1} \\
\dot{m}_{2, j+1} \\
\dot{m}_{3, j+1} \\
\vdots \\
\dot{m}_{N, j+1}
\end{array}\right)=\left(\begin{array}{c}
\dot{m}_{t o t} \\
0 \\
0 \\
\vdots \\
0
\end{array}\right)
$$

where $\quad k$ is a hydraulic resistance coefficient $\left[\mathrm{kg}^{-1} \mathrm{~m}^{-1}\right]$,

$j$ subscript denotes the iteration number.

The hydraulic resistance coefficient $k_{i}$ is defined so that the product $\left(k_{i} \cdot \dot{m}_{i}{ }^{2}\right)$ corresponds to the pressure drop (in Pascal) along the entire $i$-th hydraulic path. The value of $k_{i}$ is representative of the pressure drop along the $i$-th collector row, which is proportional to the square of the row flow rate $\dot{m}_{i}$, as well as the pressure drop across the supply/return pipes segments and tees included in the $i$-th hydraulic path, properly normalized to the flow rate $\dot{m}_{i}$. In general, $k_{i}$ is defined by a formulation of the type (Eq. 13 ):

$$
k_{i}=k_{i}^{\prime}+\sum_{y=1}^{i}\left(k_{y}^{\prime \prime} \frac{\dot{m}_{y-1 \rightarrow y}^{2}}{\dot{m}_{i}^{2}}\right)
$$

where $k_{i}^{\prime}\left[\mathrm{kg}^{-1} \mathrm{~m}^{-1}\right]$ is the contribution to the coefficient $k_{i}$ such that the product $\left(k_{i}^{\prime} \cdot \dot{m}_{i}{ }^{2}\right)$ gives the pressure drop in those components whose pressure drop is proportional to the square of the row flow rate, such as collectors, row inlet/outlet, balancing valves, etc. pressure drop in the components of the $(y-1 \rightarrow y)$-th distribution line segment, such as supply/return pipe segments and tee junctions, $y-1 \rightarrow y$ subscript denotes the supply/return pipe segment between the $(y-1)$-th and $y$-th collector row.

The system of equations (Eq. 12) is iteratively solved until the maximum difference in the collector row flow rates between two consecutive iterations is lower than $0.1 \%$. Assuming a collector array with 24 hydraulic paths, such as that used in this study, a typical calculation is performed in approximately 0.1 seconds for a computer with quad-core CPU and $2.4 \mathrm{GHz} \mathrm{CPU}$ frequency.

The Matlab code of the model is publicly available online (Bava, 2016).

\subsection{Description of the solar collector field}

\subsubsection{Collector field layout}

The developed model was based on the layout of the solar collector field near Høje Taastrup (Denmark). The layout of the collector field is shown in Figure 3. The collector field had a collector area of $3024 \mathrm{~m}^{2}$ and consisted of two subfields, having 12 collector rows each. Each row was made up of 10 HTHEATStore 
35/08 collectors (Section 2.1.1) and the row distance was $5.5 \mathrm{~m}$. The collectors had a tilt angle of $43^{\circ}$ and an orientation of $2.5^{\circ} \mathrm{W}$. The supply pipes ran along the outer sides of the collector field (blue lines in Figure 3). One return pipe collected the fluid in the middle of the field (red line in Figure 3). Pumps, heat exchanger, expansion vessels and control system were located in the technical building in the north-east corner of the collector field. Because there was no auxiliary heating plant nearby, the outlet temperature from the collector field had always to reach approximately the DH supply temperature. The collector field was usually operated between an inlet temperature of $50-55{ }^{\circ} \mathrm{C}$ and an outlet temperature of $90-95{ }^{\circ} \mathrm{C}$. The flow rate ranged

Figure 3: Layout of Høje Taastrup solar collector field: blue and red lines represent supply and return pipes respectively (adapted from Arcon-Sunmark A/S).

The distribution pipes were made of preinsulated steel pipes. The pipes between the technical building and the collector field, along which the entire field flow rate flows, had an inner diameter of $10.7 \mathrm{~cm}$. The diameter progressively decreased as part of the flow rate was diverted to the collector rows. For each collector row the supply line had a diverging tee junction which directed part of the supplied fluid to the collector row through the row inlet. The row inlet consisted of two preinsulated steel pipes, connected to each other through a balancing valve. The balancing valves installed in the collector field were of type STAD20 from row 1 to 11 and STAD25 from row 12 to 24 (IMI Hydronic, 2015a). In the middle of the field, the flows coming from each couple of side-by-side rows merged through a merging tee junction and flowed into the return pipe through a converging tee junction. Before the merging tee junction, each row outlet was equipped with a three way ball valve. This valve, together with the balancing valve at the row inlet, could be used to isolate a specific row from the rest of the field, when maintenance was needed.

286 The heat transfer fluid in the collector field was a 35\% propylene glycol/water mixture (Section 2.1.2).

\subsubsection{Measuring equipment}

To measure the flow rate in the different collector rows, a differential pressure sensor TA-SCOPE from IMI Hydronic was used (IMI Hydronic, 2015b). The balancing valves are equipped with two measuring points, one before and one after the valve member. From the measured pressure drop across the valve and the valve flow factor (Eq. 4), the flow rate is calculated. The TA-SCOPE device is also equipped with a temperature sensor, so that, by specifying the type of fluid, it calculates its density and viscosity and corrects the flow factor accordingly. The nominal accuracy of the differential pressure sensor is given by the higher value between $0.1 \mathrm{kPa}$ and $1 \%$ of the measured value. However, when using the TA-SCOPE sensor to evaluate the flow rate across a STAD valve, the accuracy is worse. Figure 4 shows the expected uncertainty as function of the valve setting. As the uncertainty increases sharply at low valve settings, it is generally advised to use a 
setting higher than two. This rule of thumb was respected in Høje Taastrup collector field, where the lowest valve setting was 2.2 .

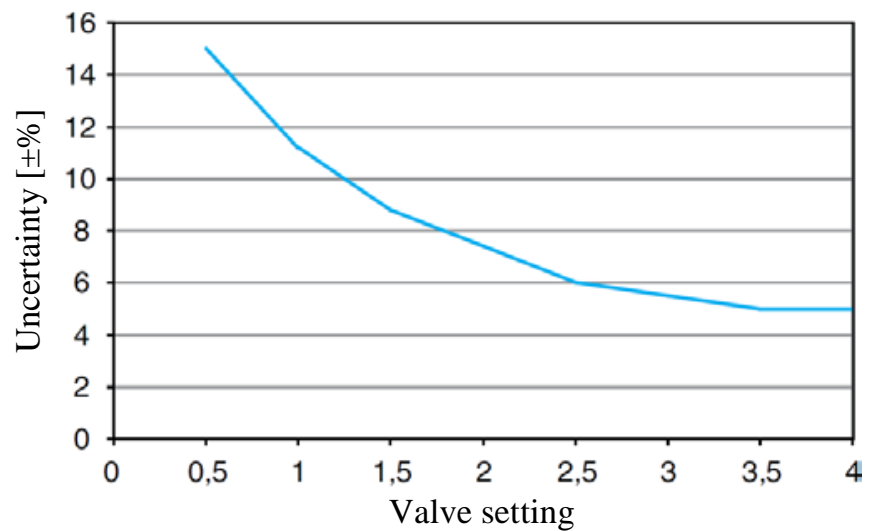

Figure 4: Uncertainty on the measured flow rate across a STAD valve as function of the valve setting (IMI Hydronic, 2015a).

A first series of measurements on the field flow distribution showed that the difference in the row flow rates was lower than the uncertainty of the measurement method. A validation of the model in these conditions would not have been completely decisive, as the error band of the measured points would be larger than the differences in flow rate that the model is meant to predict. Consequently, a second series of measurements was carried out. This time the setting of the first 10 balancing valves in the eastern subfield were modified, so to induce a stronger flow maldistribution, which could be more easily detected.

As the total field flow rate was expected to be the most important parameter affecting the flow distribution, three different flow rates were tested: a high flow rate of approximately $50 \mathrm{~m}^{3} \mathrm{~h}^{-1}$, which is the highest flow rate supplied to the field in full load conditions; a low flow rate of $14 \mathrm{~m}^{3} \mathrm{~h}^{-1}$, which was regarded as the lowest flow rate still able to cause a pressure drop across the valves high enough to make the measurement meaningful; and an intermediate flow rate of $30 \mathrm{~m}^{3} \mathrm{~h}^{-1}$. As measuring the flow rate in all the rows took approximately 30-40 minutes, it was important that the operating conditions of the collector field were kept as constant as possible during this procedure. Hence, the measurements were performed during a cloudy day, to avoid significant temperature variations, and the pump was run at constant speed. The relevant operating conditions during the tests are listed in Table 1.

Table 1: Operating conditions while measuring the field flow distribution in Høje Taastrup solar collector field.

\begin{tabular}{lccc}
\hline & Test 1 & Test 2 & Test 3 \\
\hline Duration [min] & 29 & 32 & 38 \\
Field flow rate $\left[\mathrm{m}^{3} \mathrm{~h}^{-1}\right]$ & $50.3 \pm 0.3 \%$ & $30.4 \pm 0.3 \%$ & $14.1 \pm 0.6 \%$ \\
Inlet temperature $\left[{ }^{\circ} \mathrm{C}\right]$ & $45.0 \pm 1.2$ & $46.7 \pm 1.2$ & $50.0 \pm 0.5$ \\
Outlet temperature $\left[{ }^{\circ} \mathrm{C}\right]$ & $45.1 \pm 1.2$ & $47.5 \pm 1.3$ & $50.5 \pm 0.6$ \\
\hline
\end{tabular}

319 The volume flow rate to the collector field was measured by an electromagnetic flow meter with an accuracy of $0.5 \%$. The fluid temperature was measured by RTD temperature sensors with accuracy of $0.25{ }^{\circ} \mathrm{C}$. The temperature was monitored at the beginning of the supply pipe and at the end of the return pipe, as well as at the inlet and outlet of four collector rows. The pressure in the system was measured by piezoresistive pressure sensor with maximum accuracy of $0.5 \%$. In the solar collector loop there were three of these sensors: one after the pump, one right before the heat exchanger and one after the heat exchanger. The first and the second sensor could hence be used to evaluate the pressure drop across the collector field.

326 The instantaneous values of the monitored data were recorded once per minute. 
- Case 1. The operating conditions used for the simulation were similar to those actually used in Høje Taastrup collector field. The inlet temperature was $55^{\circ} \mathrm{C}$ and the solar irradiance on the collector plane was varied with the total flow rate in such a way that the outlet temperature was approximately $95{ }^{\circ} \mathrm{C}$ (see (Eq. 11)). A 35\% propylene glycol/water mixture was assumed as collector fluid (Eq. 5-Eq. 7). The same settings of the balancing valves as used in Høje Taastrup in case of normal operation were assumed in the model.

- Case 2. The effect of a fluid temperature close to the freezing point was investigated. In case of very cold temperatures, the solar collector fluid is circulated in the collector loop to prevent freezing. Collector rows supplied with lower flow rates are more likely to freeze in case of extended cold periods. As the viscosity of propylene glycol/water mixtures is strongly dependent on the temperature, it is important to verify that also in these conditions all collector rows receive a sufficient flow. According to DOW (2008), the freezing point of a 35\% propylene glycol/water mixture should is $-16{ }^{\circ} \mathrm{C}$. Consequently, a slightly higher fluid temperature of $-13{ }^{\circ} \mathrm{C}$ was assumed in the model simulations.

- Case 3. The operating conditions were the same as in case 1, but no balancing valves were installed. A method for achieving good flow distribution without balancing valves consists in keeping constant the diameters of the supply and return pipes throughout their length. This approach was for example used in the first large collector fields built in Sweden (Section 1.2).

This case was divided in two subcases. Subcase 3.1 used the same distribution pipes as in case 1, so the pipe diameter changed along the pipe length. In subcase 3.2 constant diameters in supply and return pipes were assumed, more specifically $8.25 \mathrm{~cm}$ for the supply pipe and $10.7 \mathrm{~cm}$ for the return pipe. Additionally, to avoid unbalance between the two subfields, the technical building was assumed to be located right above where row 1 and 13 face each other (see Figure 3).

- Case 4. The number and the composition of the collector rows were the same as in the previous cases, but the rows were now all connected in parallel. The resulting layout is shown in Figure 5. Three different subcases were investigated. In subcases 4.1 and 4.2 the diameter of the supply and return pipes was progressively decreased as more fluid was diverted. The diameters of the pipes were chosen from commercially available preinsulated pipes (Logstor, 2005) and in such a way that the highest fluid velocity was lower than $1.65 \mathrm{~m} / \mathrm{s}$. The difference between the two subcases was that in subcase 4.1 balancing valves were regulated to obtain a more uniform flow distribution at the flow rate of $50 \mathrm{~m}^{3} \mathrm{~h}^{-1}$. In subcase 4.2 no valves were used. Finally, in subcase 4.3 the diameter of the distribution pipes was kept constant and equal to $10.7 \mathrm{~cm}$, i.e. the largest pipe diameter used in subcases 4.1 and 4.2. The operating conditions were the same as in case 1. 


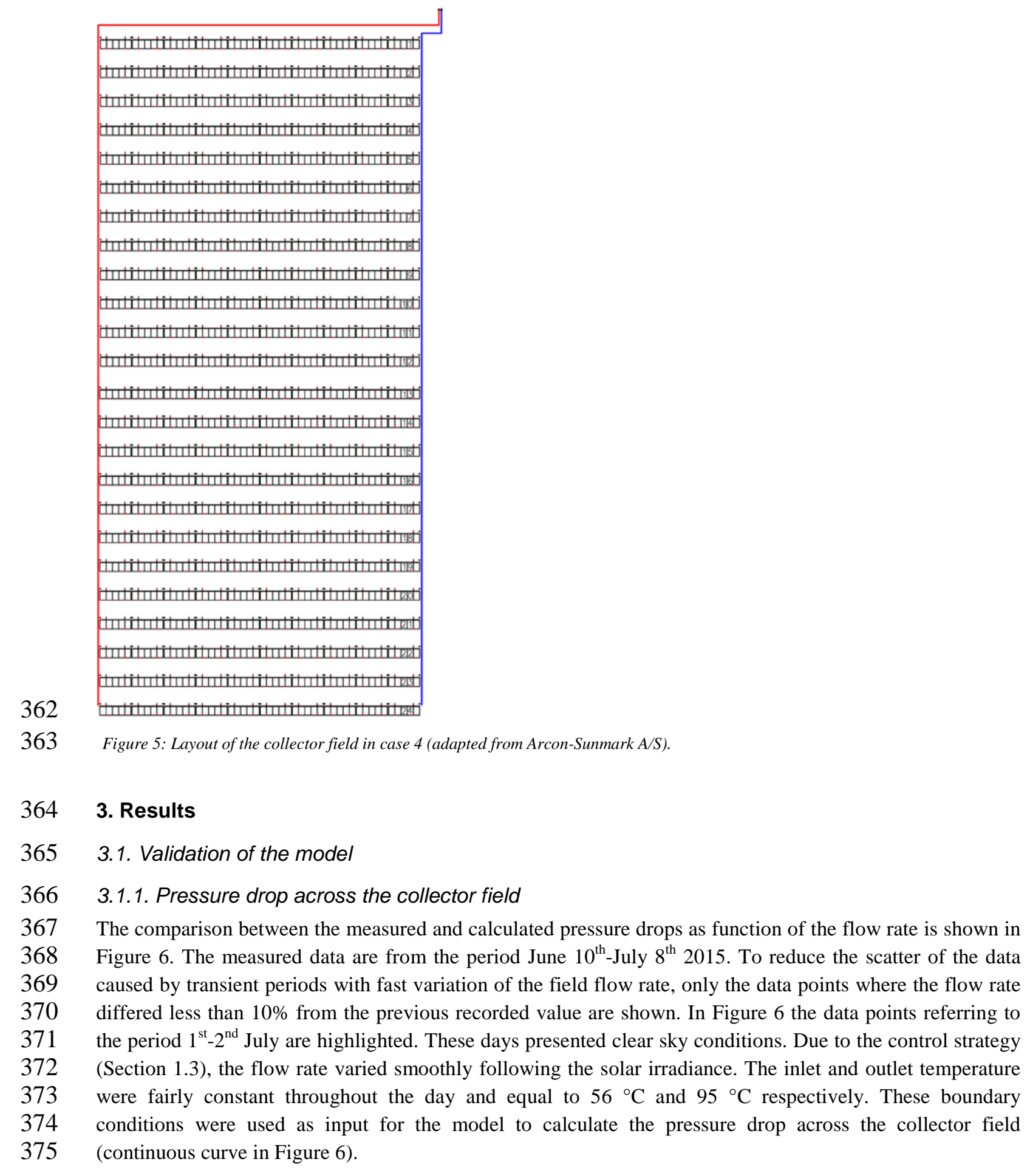




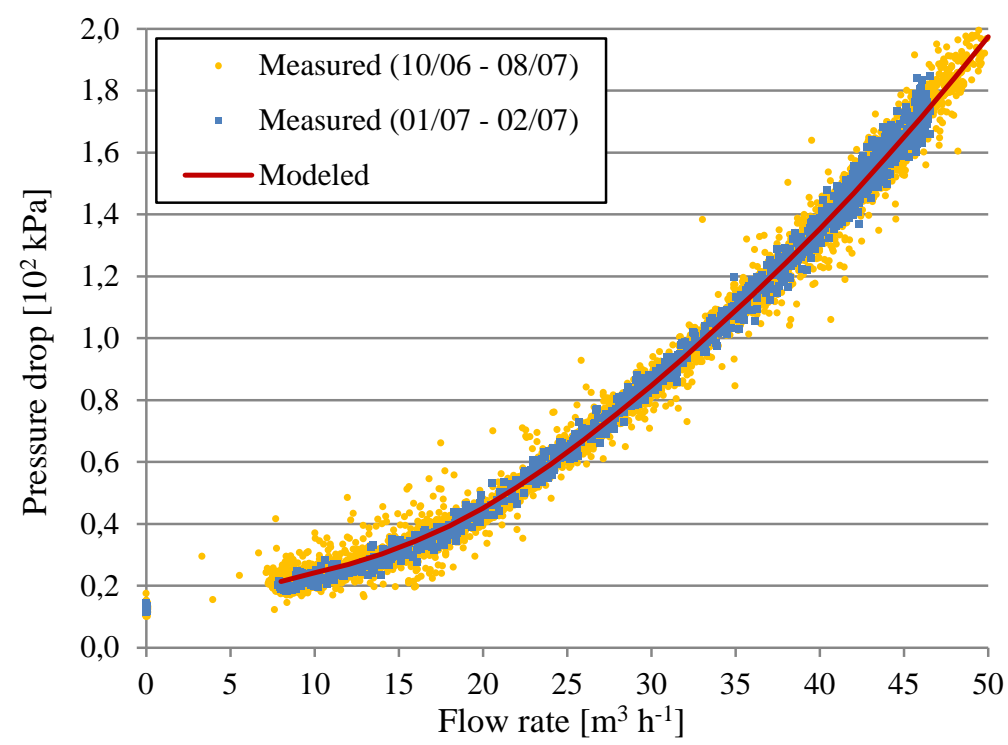

Figure 6: Comparison between measured and modeled pressure drop across Høje Taastrup collector field as function of the field flow rate.

379 At null flow the measured pressure difference was approximately $13 \pm 1 \mathrm{kPa}$. This was because the two 380 manometers (see Section 2.2.2) had an elevation difference of $1.36 \mathrm{~m}$, which caused different hydrostatic pressures. Apart from this offset, the typical quadratic relation between pressure drop and flow rate was observed, as the measured points are approximately aligned along a parabolic trajectory.

383 The pressure drop curve calculated by the model fits the measured data accurately. The coefficient of 384 determination $R^{2}$ between the measured data and the model is 0.97 , if the entire data set is used, and 0.98 , if only data from the period $1^{\text {st }}-2^{\text {nd }}$ July are used.

\section{$386 \quad 3.1 .2$. Flow distribution}

The flow distribution was expressed in terms of dimensionless flow rate in the collector rows, defined as:

$$
V_{i}^{\prime}=\frac{V_{i}}{\left(\sum_{i=1}^{N} V_{i}\right) / N}
$$

where $\quad V_{i}^{\prime}$ is the dimensionless flow rate in the $i$-th collector row [-],

$V_{i}$ is the volume flow rate in the $i$-th collector row $\left[\mathrm{m}^{3} \mathrm{~h}^{-1}\right]$, $N$ is the number of collector rows [-].

Figure 7, Figure 8 and Figure 9 show the measured and modeled flow distribution in terms of dimensionless flow rate for field flow rates of 50, 30 and $14 \mathrm{~m}^{3} \mathrm{~h}^{-1}$. The shown error bars are based on the information contained in Figure 4. 


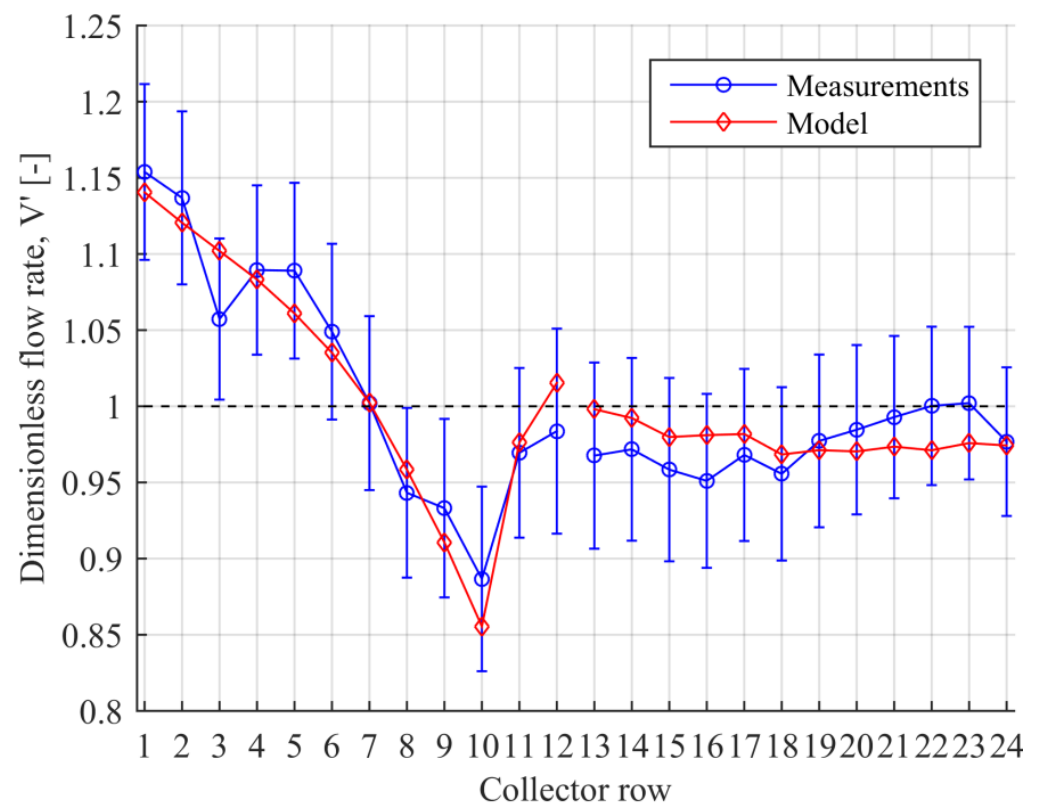

Figure 7: Comparison between measured and modeled flow distribution for a field flow rate of $50 \mathrm{~m}^{3} \mathrm{~h}^{-1}$.

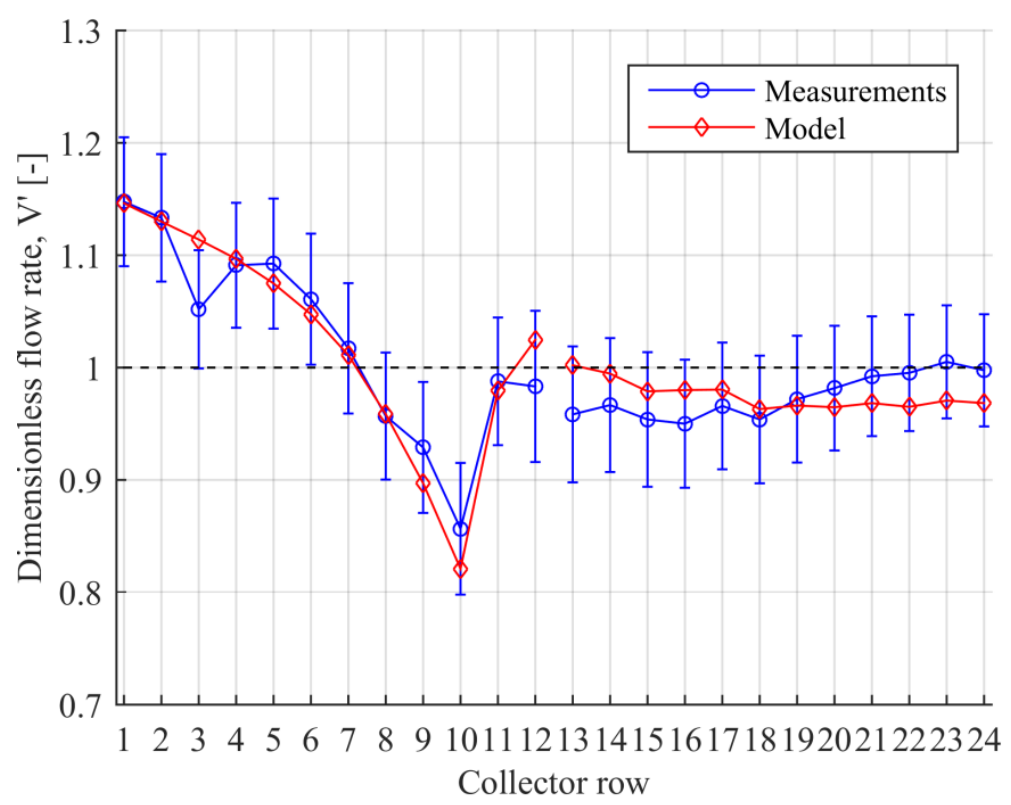

Figure 8: Comparison between measured and modeled flow distribution for a field flow rate of $30 \mathrm{~m}^{3} \mathrm{~h}^{-1}$. 


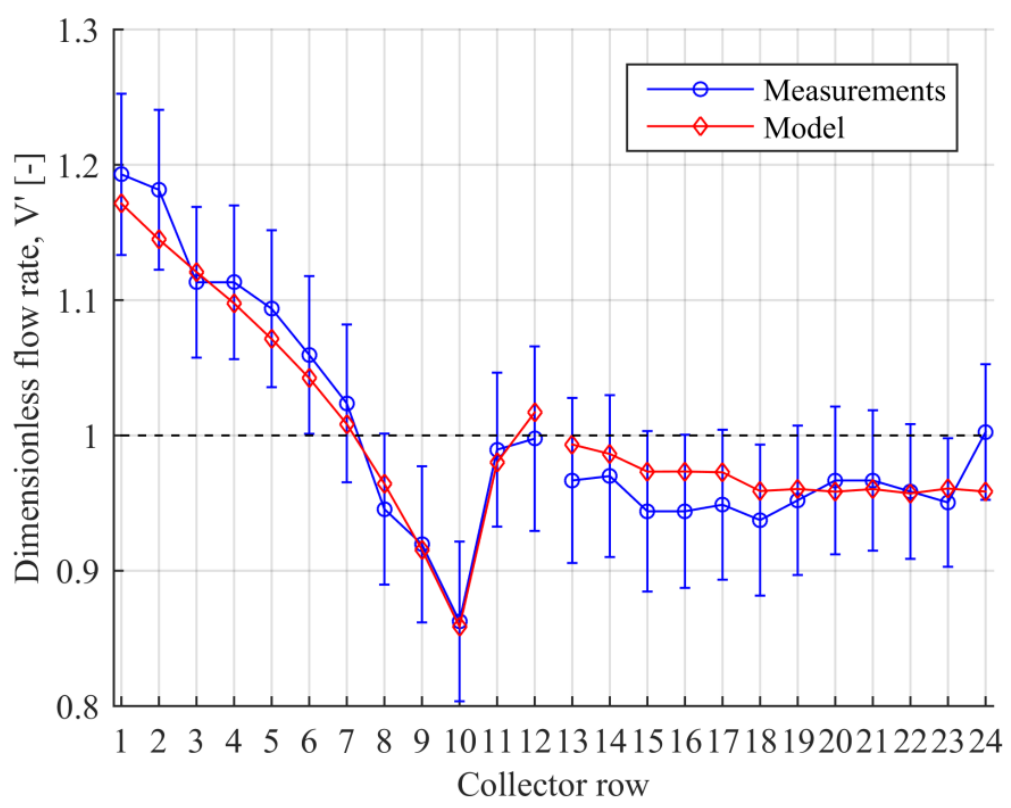

Figure 9: Comparison between measured and modeled flow distribution for a field flow rate of $14 \mathrm{~m}^{3} \mathrm{~h}^{-1}$.

The difference in flow distribution between the eastern subfield (rows 1-12) and the western subfield (rows 13-24) is easily recognized. In the eastern subfield the valve settings were changed so to introduce a stronger maldistribution than in normal operation. The settings of the first 10 valves were modified, so to cause a decreasing flow rate profile. In the western subfield the valve settings were not changed, so the flow distribution was much more uniform.

406 To evaluate the accuracy of the model, the root-mean-square deviation (RMSD) is introduced (Eq. 15).

$$
R M S D=\sqrt{\frac{\sum_{i=1}^{N}\left(\hat{z}_{i}-z_{i}\right)^{2}}{N}} \quad \text { (Eq. 15) }
$$

408 where $z$ is the measured value of the investigated parameter,

$409 \quad \hat{z}$ is the estimator of the investigated parameter.

410 To make the different RMSDs immediately comparable irrespective of the field flow rate, the RMSDs were 411 evaluated using the dimensionless flow rate $V^{\prime}$ (Eq. 14). Table 2 lists the RMSDs and the maximum relative 412 difference for the three flow distribution tests.

413 Table 2: RMSD and maximum deviation between measured and modeled flow distributions in terms of dimensionless flow rates.

\begin{tabular}{lccc}
\hline & Test 1 & Test 2 & Test 3 \\
\hline Field flow rate $\left[\mathrm{m}^{3} \mathrm{~h}^{-1}\right]$ & 50.3 & 30.4 & 14.1 \\
$\mathrm{RMSD}\left(V^{\prime}\right)$ & 0.022 & 0.027 & 0.020 \\
Max. deviation (row number) & $4.2 \%(3)$ & $5.9 \%(3)$ & $4.4 \%(24)$ \\
\hline
\end{tabular}

414 An overall good agreement between measurements and model was found, with the RMSD ranging between $415 \quad 0.020$ and 0.027 . The highest deviations were between $4.2 \%$ and $5.9 \%$ depending on the tested flow rate. It is 416 also noted that at the lowest flow rate of $14 \mathrm{~m}^{3} \mathrm{~h}^{-1}$ the measured flow distribution is less uniform that in the 417 other two cases. Especially the very first rows received higher fractions of the total flow rate, with 418 dimensionless flow rates up to 1.20. Conversely, in the other two tests, this value did not exceed 1.15.

\section{3.2. Investigated scenarios}

420 3.2.1. Case 1: normal operating conditions

421 The calculated flow distribution in case 1 is shown in Figure 10 for different field flow rates. 


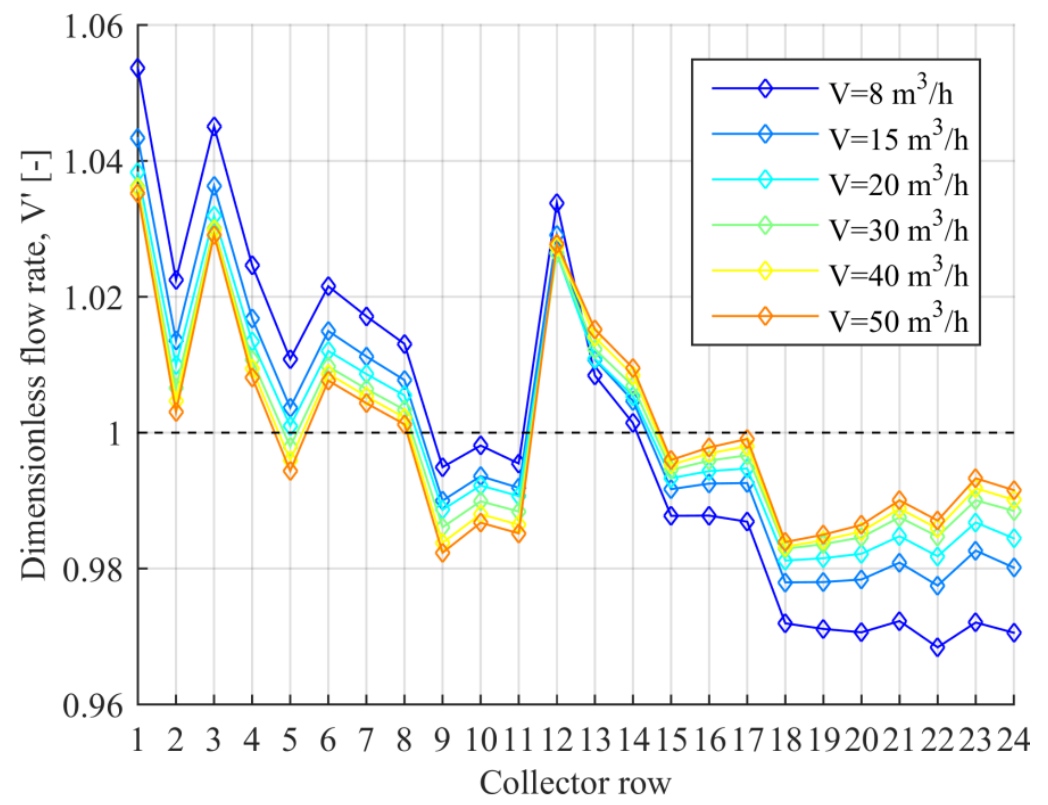

Figure 10: Modeled flow distributions in Høje Taastrup solar collector field for different field flow rates, assuming normal operating conditions (case 1).

425 In the simulated scenarios the RMSD was used as main parameter to evaluate the degree of maldistribution. Unlike in the model validation, the term of comparison was now the uniform distribution profile ( $z=1$ in Eq. 15).

428 It can be noted that the higher the flow rate, the more uniform the flow distribution. At flow rates equal to or higher than $30 \mathrm{~m}^{3} \mathrm{~h}^{-1}$ the RMSD was approximately constant and equal to 0.015 . At lower flow rates this value increased up to 0.025 for a flow rate of $8 \mathrm{~m}^{3} \mathrm{~h}^{-1}$. The highest deviation from the ideal flow rate was lower than $6 \%$, and the maximum difference between highest and lowest row flow rates was within $8 \%$.

432 For the different flow rates, the pressure drop across the field was in agreement with Figure 6.

\subsubsection{Case 2: temperature close to freezing point}

434 Figure 11 shows the model results in case 2, which differs from case 1 only in the fluid temperature, now 435 assumed constant and equal to $-13^{\circ} \mathrm{C}$.

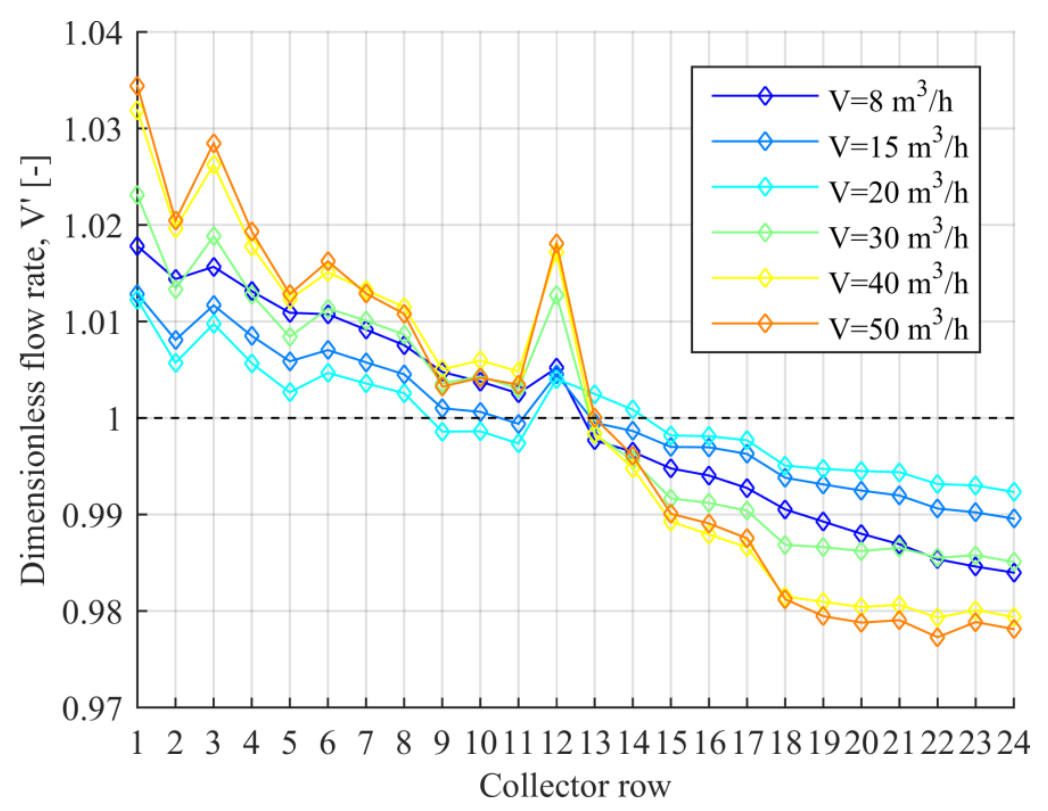

Collector row

437 Figure 11: Modeled flow distributions in Høje Taastrup solar collector field for different field flow rates in case of low temperature 438 (case 2).

439 Despite the much higher viscosity of the glycol/water mixture at low temperature, the flow distribution was 
very uniform. The maximum deviation of row flow rate from the perfectly uniform case was $3.5 \%$. Unlike case 1, higher flow rates did not necessarily entail a more uniform flow distribution. In fact, the value of RMSD varied from a minimum of 0.005 at $20 \mathrm{~m}^{3} \mathrm{~h}^{-1}$ to a maximum of 0.018 at $50 \mathrm{~m}^{3} \mathrm{~h}^{-1}$.

\subsubsection{Case 3: no balancing valves}

444 In subcase 3.1 only the balancing valves were removed, while the layout and the dimensions of the distribution pipes were maintained as in case 1. The resulting flow distributions are presented in Figure 12. Given the longer pipe length from the pump to the western subfield, this solution caused this subfield to be supplied with a much lower flow rate (12-14\% lower compared to the eastern subfield depending on the field flow rate). Within the same subfield the relative difference between the lowest and the highest collector row flow rate was $6-8 \%$ depending on the field flow rate. The RMSDs in this case were much higher, ranging between 0.068 and 0.082 .

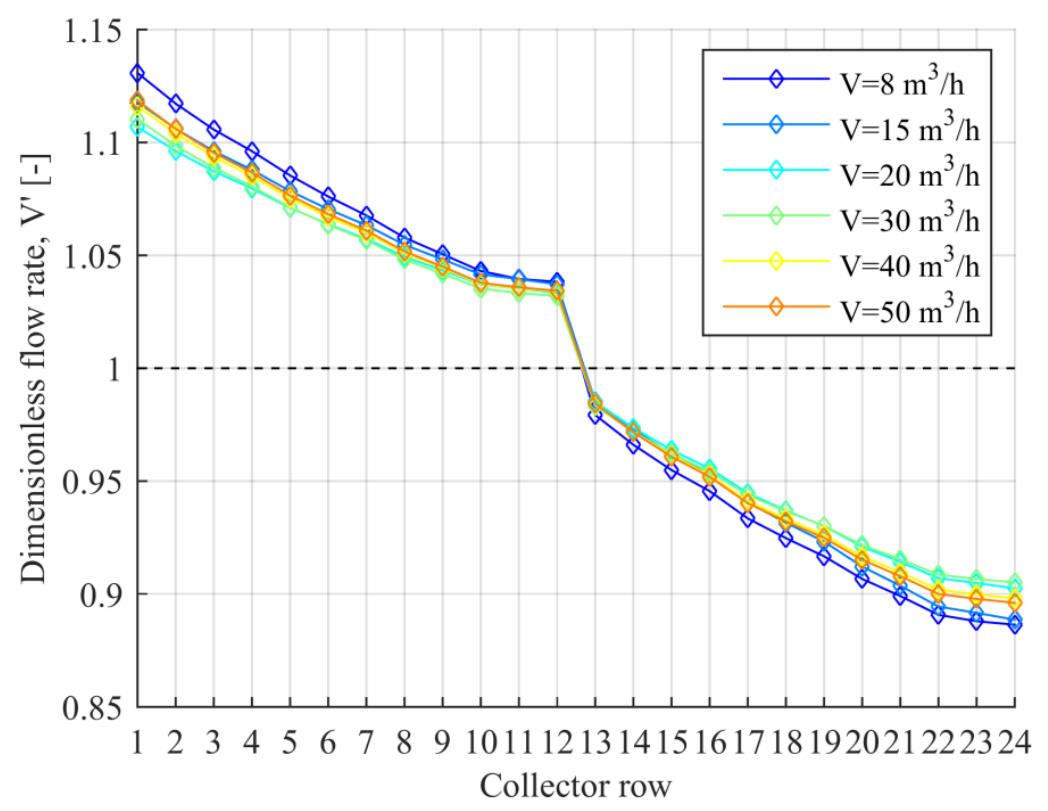

Figure 12: Modeled flow distributions for different field flow rates in subcase 3.1.

453 In subcase 3.2 the diameters of the supply and return pipes were maintained constant and each of them equal 454 to the largest installed diameter ( $8.25 \mathrm{~cm}$ for the supply pipe and $10.7 \mathrm{~cm}$ for the return pipe). Given the 455 symmetry of the resulting field layout, the flow distribution was identical in both subfields. Hence, Figure 13 456 shows the flow distribution only for the eastern subfield. Due to the constant pipe diameters, the relative difference between the lowest and the highest collector row flow rate was 5-6\% depending on the field flow rate, so slightly better than in subcase 3.1 .

459 Without balancing valves and due to the larger pipe diameters, the pressure drop across the collector field was approximately $20-25 \%$ smaller compared to case 1 . However, as the connection to the DH network is located in the north-east corner of the field, the additional $2 \times 65 \mathrm{~m}$ pipes to carry the fluid to this point would result in a reduction of $10 \%$ only. 


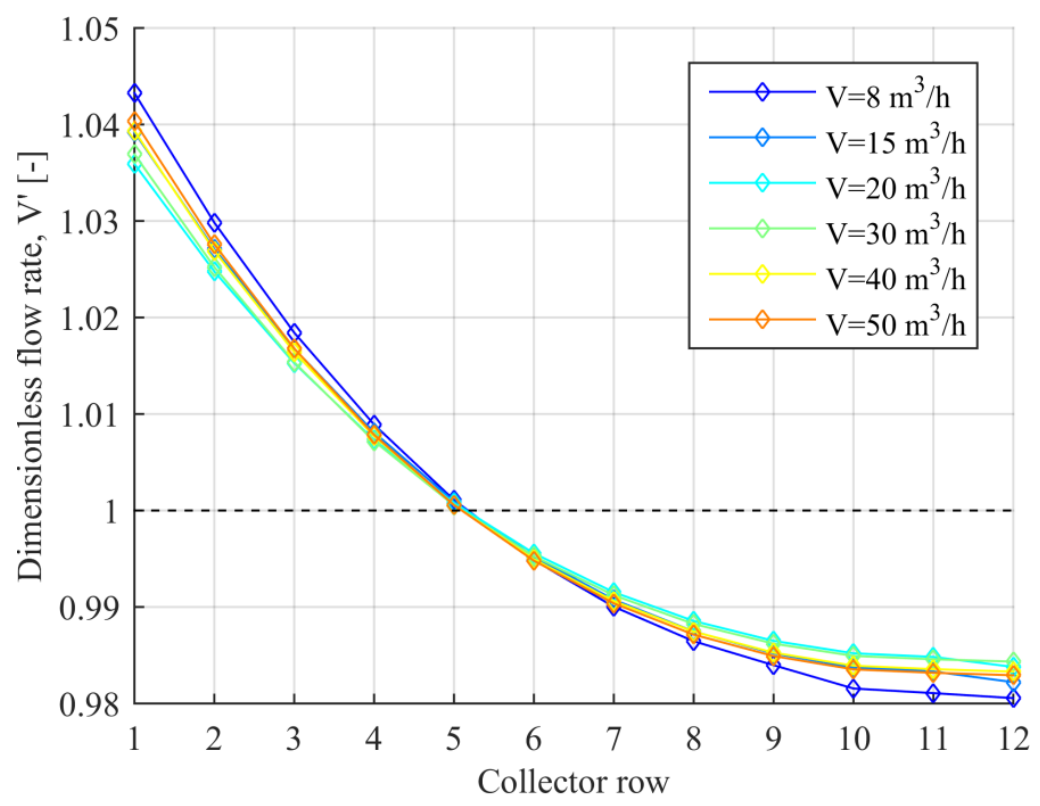

Figure 13: Modeled flow distributions for different field flow rates in subcase 3.2.

\subsubsection{Case 4: different field layout: 24 rows in parallel}

Looking at Figure 13 it may be thought that balancing valves are not strictly necessary to reach a good flow distribution. For this reason, a different collector field layout (Figure 5) was investigated to verify whether this could be generalized. Figure 14 presents the flow distributions in subcase 4.1 with balancing valves, subcease 4.2 without balancing valves and subcase 4.3 without balancing valves and constant distribution pipe diameter. For each subcase the two flow rates, which gave the most and least uniform distribution, are 471 shown.

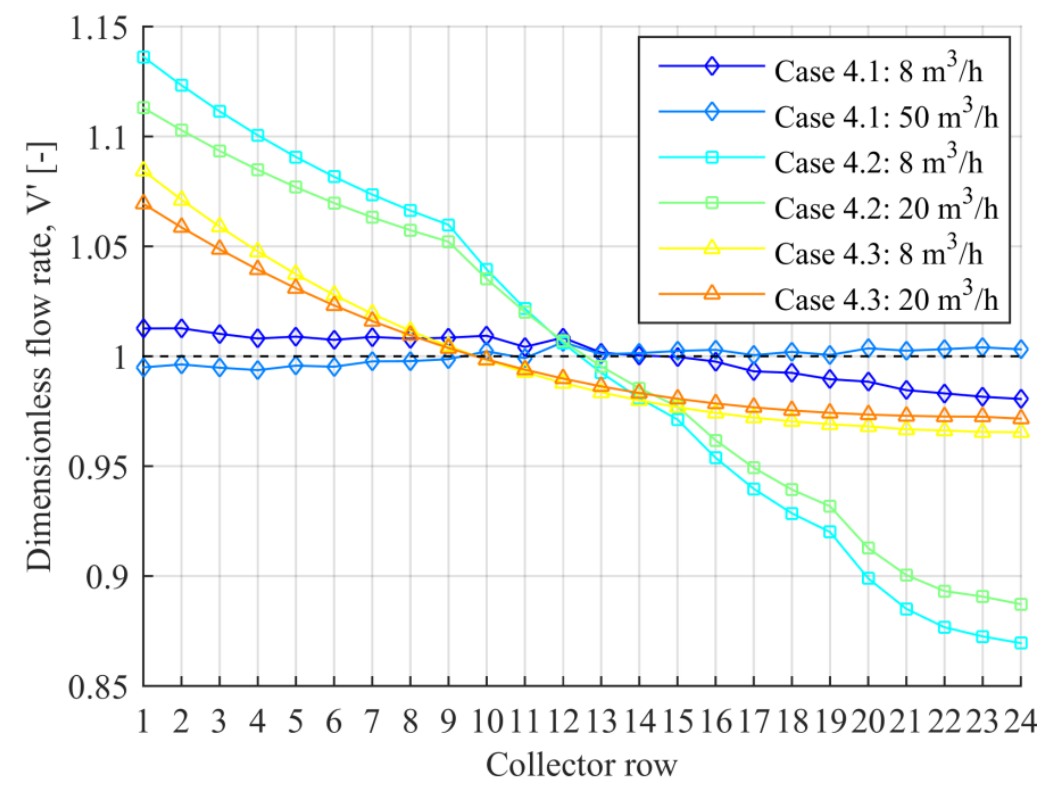

Figure 14: Modeled flow distribution in the different subcases of case 4. Case 4.1 with balancing valves; Case 4.2 without balancing valves and decreasing diameter of the distribution pipes; Case 4.3 without balancing valves and constant diameter of the distribution pipes and equal to the larger pipe diameter of Case 4.2.

476 It can be noted that only subcase 4.1, which makes use of balancing valves, gave a uniform flow distribution. As expected the better distribution was found for the flow rate of $50 \mathrm{~m}^{3} \mathrm{~h}^{-1}\left(\mathrm{RMSD}=3.5 \cdot 10^{-3}\right)$, at which the balancing valves were regulated. In this case the flow rate in each row never differed more than $1 \%$ from the perfectly uniform distribution. This deviation increased at lower flow rates and at $8 \mathrm{~m}^{3} \mathrm{~h}^{-1}$ it was within $2 \%$, while the RMSD was 0.01 .

481 Removing the balancing valves while decreasing the distribution pipe diameter with the flow rate (subcase 
4.2) gave the highest maldistribution, with deviations up to $13 \%$ compared to perfectly uniform distribution.

483 Comparing the highest and the lowest row flow rate, the former was about $30 \%$ higher than the latter. The 484 RMSD was 0.086 at $8 \mathrm{~m}^{3} \mathrm{~h}^{-1}$ and 0.073 at $20 \mathrm{~m}^{3} \mathrm{~h}^{-1}$. Maintaining constant diameter along the entire length of 485 the distribution pipes (subcase 4.3) improved the flow distribution compared to subcase 4.2, and the highest 486 row flow rate was $12 \%$ higher than the lowest row flow rate. The RMSDs decreased to 0.036 and 0.030 at 8 and $20 \mathrm{~m}^{3} \mathrm{~h}^{-1}$, but were still considerably higher than in case 4.1.

\section{Discussion}

\subsection{Validation of the model}

490 From Figure 7, Figure 8, Figure 9 and Table 2, an overall good agreement between modeled results and measurements can be noted, with the RMSD ranging between 0.020 and 0.027 .

492 In the eastern subfield the measured and modeled flow distribution profiles presented the same trend, with the only exception represented by the third row. In fact, this collector row was characterized by the highest deviation between measured and modeled flow rate in both test 1 and 2 (Table 2). For this row the measured flow rate was significantly lower than the flow rate in the neighboring rows in all the three tests. This was most likely due to some additional flow resistance in this collector row, maybe due to some obstruction or dirt clog. In fact, also the original setting of its balancing valve was larger (and hence the valve more open) than the valve settings of neighboring rows and had the same value as the valve in the $11^{\text {th }}$ collector row, significantly farther away. This means that, already when balancing the flow at the start-up phase of the collector field, it was noted that, in order for the third row to receive the design flow rate, its valve had to be opened more than expected. It is not reasonable to assume that this difference was caused by an inaccurate correlation for its tee junction used by the model. In fact, being the two subfields symmetric, a similar behavior should appear in the corresponding collector row (the $15^{\text {th }}$ ) in the western subfield.

At the lowest flow rate, row 24 had the highest deviation between measurement and model (Table 2). In this case the accuracy of the differential pressure sensor might play a significant role. Given the low flow rate and the completely open balancing valve, the pressure drop across the valve was very low $(0.5 \mathrm{kPa})$. As the accuracy of the TA-SCOPE sensor is $0.1 \mathrm{kPa}$ (Section 2.2.2), the measurement error can be higher than that shown in Figure 4.

510 Comparing the scenario in normal operating conditions (Figure 10) with the validation results (Figure 7, 511 Figure 8 and Figure 9), it can be seen that the correct setting of the balancing valves significantly improved 512 the flow distribution.

513 The most uniform flow distribution occurred at the highest flow rate of $50 \mathrm{~m}^{3} \mathrm{~h}^{-1}$. This was expected, as the 514 balancing valves were set to give a uniform distribution at the nominal field flow rate, i.e. the highest flow 515 rate the collector field operates at. This was about $55 \mathrm{~m}^{3} \mathrm{~h}^{-1}$ in Høje Taastrup collector field.

516 As the relation between flow rate and pressure drop varies differently for the different components in the collector loop, a higher maldistribution is likely to occur when the field flow rate increasingly deviates from the nominal one. Despite this, the balancing valves resulted in a good flow distribution in all simulated conditions. The highest relative difference between row flow rate and its ideal value was always well within $10 \%$, which is considered the maximum acceptable deviation according to the German standard VDI (2004).

A good flow distribution was found also in case 2 (Figure 11) with low fluid temperature. A variation in flow distribution could have been expected, due to strong temperature dependence of the kinematic viscosity of the glycol/water mixture. In fact, this increased approximately 20 times when the mixture temperature decreased from $75^{\circ} \mathrm{C}$ to $-13^{\circ} \mathrm{C}$. Despite the very strong variation, all components in the circuit experienced this low viscosity, so the flow distribution was not significantly affected.

The effect of removing the balancing valves was investigated in case 3.1 (Figure 12). There was a significant flow unbalance between the two subfields, because the supply pipe to the western subfield was $122 \mathrm{~m}$ longer compared to the eastern subfield. If a collector field with the same layout as in Høje Taastrup was designed without balancing valves, the distribution pipes should be symmetrical to avoid unbalance between the two 
subfields (case 3.2). This scenario was inspired by the first collector fields built in Sweden, such as Falkenberg and Nykvarn II. These plants were built connecting in parallel collector rows of 10 collectors each. The collectors had a U-type harp design, very similar to a HTHEATstore 35/08. Both plants were relatively small $\left(5500 \mathrm{~m}^{2}\right.$ in Falkenberg and $3500 \mathrm{~m}^{2}$ in Nykvarn II) and could achieve a uniform flow distribution without balancing valves, due to the regular layout and constant pipe diameter. Similarly, case 3.2 presented an acceptable flow distribution, as shown in Figure 13. This was possible due to the relatively small area of the collector field $\left(3024 \mathrm{~m}^{2}\right)$ and the limited number of rows connected in parallel (12 in each subfield). In this configuration the pressure drop across the collector row played the most significant role, representing $85-88 \%$ of the entire pressure drop along the hydraulic path for the first row and $76-81 \%$ for the last one. The required head of the pump in case 3.2 was $10 \%$ lower than in case 1.

However, collector fields having more collector rows connected directly in parallel are less likely to achieve uniform flow distribution (case 4.2 and 4.3), unless balancing valves are installed (case 4.1). Maintaining a large and constant diameter for the entire length of the distribution pipes help reduce the maldistribution (case 4.3), but this solution entails higher cost and heat losses due to the increased pipe size.

Comparing the results of simulations with different layouts, it was found that in absence of balancing valves the rule of thumb (Eq. 16) is generally valid, if the flow regime both in the distribution pipes and in the collectors is turbulent.

$$
\frac{\max \left(V_{i}\right)-\min \left(V_{i}\right)}{\max \left(V_{i}\right)} \approx 0.5 \frac{\Delta p_{\text {distr.pipe }}}{\Delta p_{\text {row }}} \quad \text { (Eq. 16) }
$$

where $\max \left(V_{i}\right)$ is the highest volume flow rate in a collector row $\left[\mathrm{m}^{3} \mathrm{~h}^{-1}\right]$, $\min \left(V_{i}\right)$ is the lowest volume flow rate in a collector row $\left[\mathrm{m}^{3} \mathrm{~h}^{-1}\right]$, $\Delta p_{\text {distr.pipe }}$ is the pressure drop along the longest distribution pipe supplying a collector row [Pa], $\Delta p_{\text {row }}$ is the pressure drop across a collector row supplied by the average flow rate [Pa],

For example, in order for the highest and the lowest row flow rate to differ less than $10 \%$, the pressure drop along the longest supply and return pipes should be lower than $20 \%$ of the pressure drop across the average collector row. Figure 15 represents (Eq. 16) and shows the investigated scenarios 3.2, 4.2 and 4.3 along with other selected cases, to make the data set more complete.

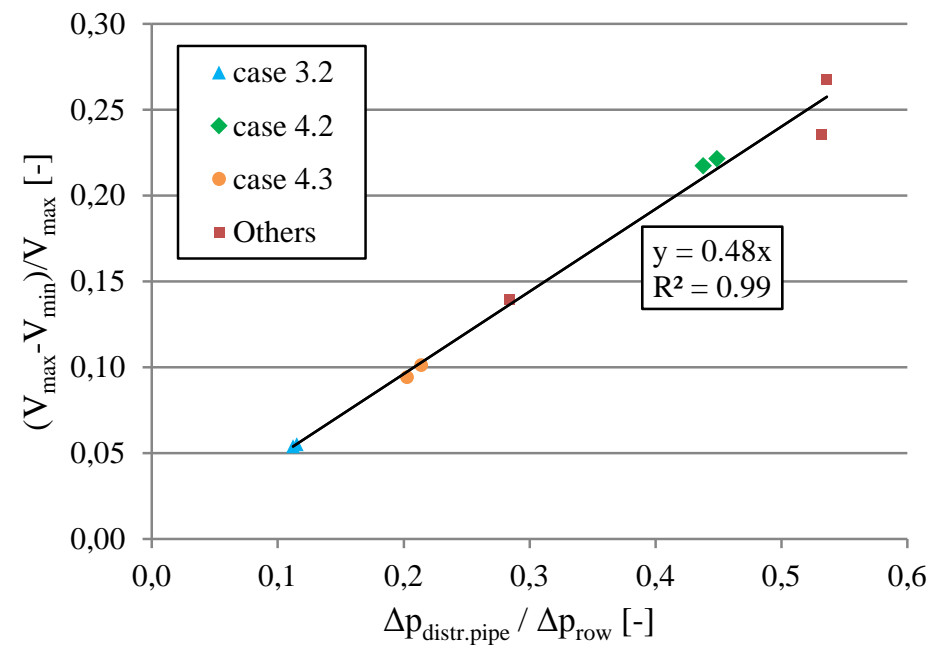

Figure 15: Maximum deviation in row flow rate as function of the ratio between the pressure drop along the longest distribution line and the average pressure drop in a collector row.

\subsection{Effect of the flow regime on the flow distribution}

From Figure 12 and Figure 13 it can be noted that, in absence of balancing valves, higher flow rates did not necessarily entail a more uniform flow distribution. Figure 13 shows that the lowest flow rate had the highest maldistribution. Increasing the flow rate up to $20 \mathrm{~m}^{3} \mathrm{~h}^{-1}$ gave a more uniform flow distribution, while for even higher flow rates this became less uniform. To analyze this trend in more detail, Figure 16 shows the RMSD as function of both flow rate and average $R e$ in the absorber pipes of the collectors. The diagram was 
based on the same collector field layout and operating conditions as in case 3.2, with the only difference of the fluid temperature, assumed constant and equal to $55^{\circ} \mathrm{C}$. This allowed having the same $R e$ in all the collectors of the same row and simplified the analysis.

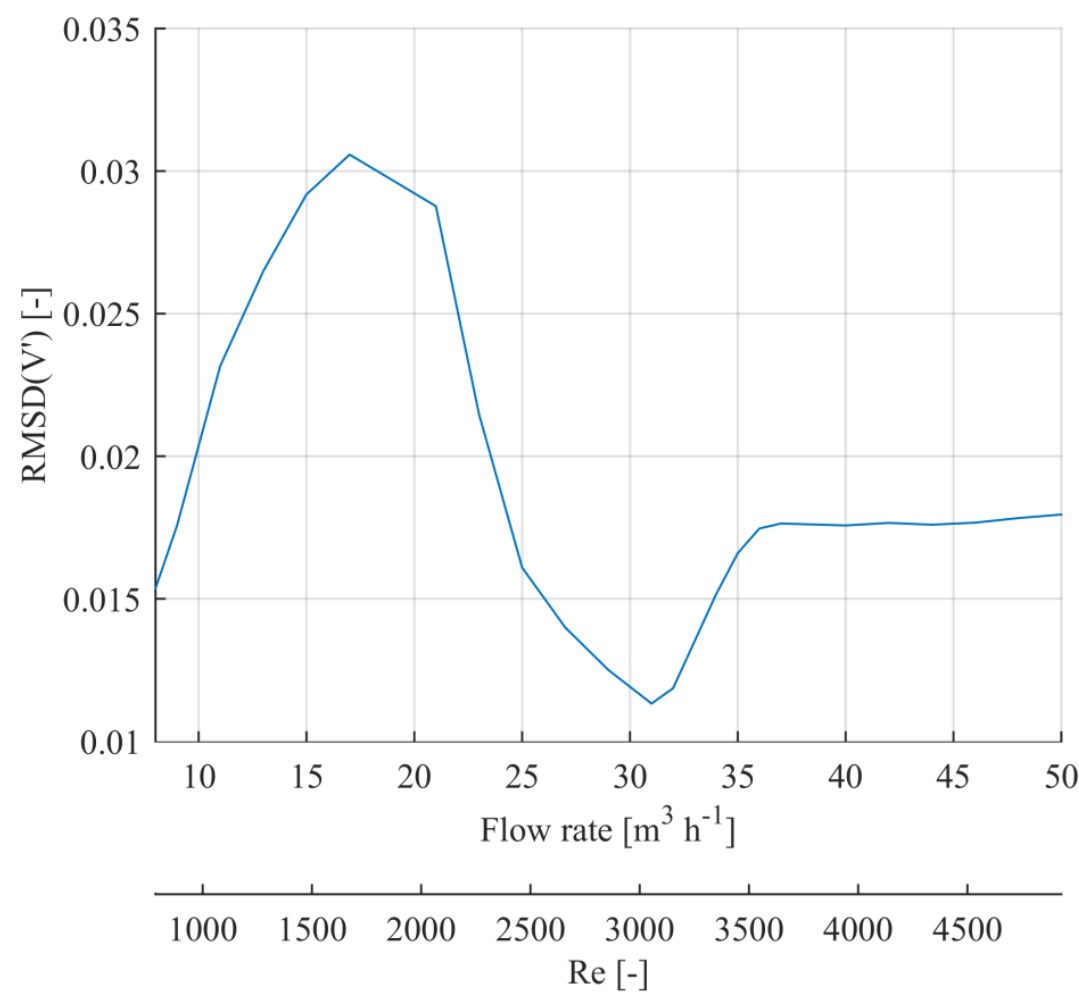

Figure 16:Profile of the RMSD of the dimensionless flow rate V' as function of the field flow rate and average Reynolds number in the collector absorber pipes.

At low flow rates $\left(V<20 \mathrm{~m}^{3} \mathrm{~h}^{-1}\right)$, the flow regime in the collectors was still laminar while that in the distribution pipes was mainly turbulent with the exception of the very last pipe segments. In these conditions, a higher field flow rate increased the flow maldistribution. In fact, the increase in pressure drop in the distribution pipes (approximately quadratic with the flow rate in turbulent regime) was sharper than that in the collector rows (approximately linear in laminar regime). At higher flow rates $\left(V=20-30 \mathrm{~m}^{3} \mathrm{~h}^{-1}\right)$, the regime in the collector absorber pipes became progressively transitional. Given the assumption of linear interpolation made in the transition region (Section 2.1.1), the pressure drop was proportional to the cube of the fluid velocity, so the flow distribution improved rapidly and the RMSD decreased to its minimum. Finally, when the field flow rate was high enough to cause turbulent regime in all components $\left(V \geq 35 \mathrm{~m}^{3} \mathrm{~h}^{-1}\right)$, the flow distribution became slightly less uniform and almost independent of the flow rate.

\section{Conclusions}

A model for estimating the flow distribution in a solar collector field was developed. The model results were compared against measurements, both in terms of pressure drop and flow distribution across a collector field. Good agreement was found.

By using the model, different scenarios were investigated. Installing balancing valves in each collector row proved to be a reliable way to guarantee uniform flow distribution. Although the valves were set in nominal conditions, the deviations occurring at different conditions were still within the generally accepted range of $\pm 10 \%$.

Relatively small fields with few collector rows and regular layout can also achieve good flow distribution without balancing valves. Keeping a constant and large pipe diameter along the entire distribution line favors a uniform distribution and decreases the pressure drop across the collector field. The final solution should be selected based on economic considerations, taking into account the cost of the pipes and valves, increased heat losses and decreased pressure drop. 
For very large collector fields with a high number of rows, balancing valves seems to be the most reliable solution to achieve good flow distribution.

\section{Acknowledgements}

The authors are thankful to the Marie-Curie Actions - Initial Training Network research programme of the European Union which supported the first author through the SolNet-SHINE project. The authors are also grateful to the company Arcon-Sunmark A/S and the DH company Høje Taastrup Fjernvarme for providing useful information necessary to develop the model and for granting access to the solar collector field in Høje Taastrup.

\section{References}

Bava, F., 2016. Field flow distribution model. <https://github.com/febav/FieldFlowDistribution> (accessed 13/07/2016).

Bava, F., Furbo, S., 2016. A numerical model for pressure drop and flow distribution in a solar collector with horizontal U-connected pipes. Sol. Energy 134, 264-272. doi:10.1016/j.solener.2016.05.012

Blasius, P.R.H., 1913. Das Aehnlichkeitsgesetz bei Reibungsvorgangen in Flüssigkeiten. Forschungsheft 131, 1-41.

Chiou, J.P., 1982. The effect of nonuniform fluid flow distribution on the thermal performance of solar collector. Sol. Energy 29, 487-502.

Clifton, J.R., Rossiter, W.J., Brown, P.W., 1985. Degraded aqueous glycol solutions: pH values and the effects of common ions on suppressing $\mathrm{pH}$ decrease. Sol. Energy Mater. 12, 77-86.

Colebrook, C.F., 1939. Turbulent flow in pipes, with particular reference to the transition region between smooth and rough pipe laws. J. Inst. Civ. Eng. 11, 133-156.

Conde, M., 2011. Thermophysical properties of brines - Models, Conde Engineering. Zurich (Switzerland) < http://www.mrc-eng.com> (accessed 13/07/2016).

Dorantes, R., García, G., Salazar, C., Oviedo, H., González, H., Alanis, R., Salazar, E., Martín-Dominguez, I.R., 2014. Thermal and hydraulic design of a solar collector field for a primary school pool. Energy Procedia 57, 2515-2524. doi:10.1016/j.egypro.2014.10.262

DOW, 2008. Engineering and Operating Guide for DOWFROST and DOWFROST HD Inhibited Propylene Glycol-based Heat Transfer Fluids <http://www.dow.com/heattrans/literature/> (accessed 13/07/2016).

EnergySupply, 2016. Danmarks største solenergianlæg på vej ved Silkeborg <http://www.energysupply.dk/article/view/235192/> (accessed 13/07/2016).

Fan, J., Shah, L.J., Furbo, S., 2007. Flow distribution in a solar collector panel with horizontally inclined absorber strips. Sol. Energy 81, 1501-1511. doi:10.1016/j.solener.2007.02.001

Furbo, S., Perers, B., Bava, F., 2015. Thermal performance of solar district heating plants in Denmark, in: Conference Proceedings of EuroSun 2014. Aix-les-Bains (France). doi:10.18086/eurosun.2014.19.11

George, J., Sastry, N. V., 2003. Densities, Dynamic Viscosities, Speeds of Sound, and Relative Permittivities for Water + Alkanediols (Propane-1,2- and -1,3-diol and Butane-1,2-, -1,3-, -1,4-, and -2,3-Diol) at Different Temperatures. J. Chem. Eng. Data 48, 1529-1539. doi:10.1021/je0340755

Haaland, S.E., 1983. Simple and Explicit Formulas for the Friction Factor in Turbulent Flow. J. Fluids Eng. 105, 89-90.

Heller, A., 2000. Large scale solar district heating evaluation, modelling and designing. PhD Thesis, Technical University of Denmark (DTU), Department of Buildings and Energy $<$ http://orbit.dtu.dk/files/5300211/R-046_PhD_Thesis.pdf> (accessed 13/07/2016).

Holman, J.P., 2002. Heat transfer, 9th ed. McGraw-Hill, New York (USA).

Idelchik, I.E., 1994. Handbook of hydraulic resistance, 3rd ed. CRC press, Boca Raton (USA).

IMI Hydronic, 2015a. STAD Balancing valves DN 15-50 <http://www.imi-hydronic.com> (accessed 13/07/2016). 
IMI Hydronic, 2014. HySelect User Manual <http://www.imi-hydronic.com> (accessed 13/07/2016).

642

643

644

645

646

647

648

649

650

651

652

653

654

655

656

657

658

659

660

661

662

663

664

665

666

667

668

669

670

671

672

673

674

675

676

677

678

679

680

681

682

683

684

ISO, 2014. ISO Standard 9806: Solar energy - Solar thermal collectors - Test methods. International Organization for Standardization (ISO), Geneva (Switzerland).

Jones, G.F., Lior, N., 1994. Flow distribution in manifolded solar collectors with negligible buoyancy effects. Sol. Energy 52, 289-300. doi:10.1016/0038-092X(94)90496-0

Joseph, D.D., Yang, B.H., 2010. Friction factor correlations for laminar, transition and turbulent flow in smooth pipes. Phys. D 239, 1318-1328. doi:10.1016/j.physd.2009.09.026

Knabl, S., Fink, C., Ohnewein, P., Mauthner, F., Hausner, R., 2014. Requirements and guidelines for collector loop installation, Deliverables of IEA-SHC Task 45 Large scale solar heating and cooling systems. IEA-SHC < http://task45.iea-shc.org/fact-sheets> (accessed 13/07/2016).

Li, H., Svendsen, S., 2013. District Heating Network Design and Configuration Optimization with Genetic Algorithm. J. Sustain. Dev. Energy, Water Environ. Syst. 1, 291-303. doi:http://dx.doi.org/10.13044/j.sdewes.2013.01.0022

Mauthner, F., Weiss, W., Spörk-Dür, M., 2016. Solar Heat Worldwide: Markets and Contribution to the Energy Supply 2014. IEA Solar Heating \& Cooling Programme $<$ http://www.ieashc.org/data/sites/1/publications/Solar-Heat-Worldwide-2016.pdf> (accessed 13/07/2016).

Melinder, Å., 2007. Thermophysical Properties of Aqueous Solutions Used as Secondary Working Fluids. PhD Thesis, Royal Institute of Technology (KTH), Department of Energy Technology.

Rohde, J.E., Knoll, R.H., 1976. Analysis of a solar collector field water flow network. Cleveland (Ohio, USA) < http://ntrs.nasa.gov/archive/nasa/casi.ntrs.nasa.gov/19760024583.pdf > (accessed 13/07/2016).

Rossiter, W.J., Godette, M., Brown, P.W., Galuk, K.G., 1985. An investigation of the degradation of aqueous ethylene glycol and propylene glycol solutions using ion chromatography. Sol. Energy Mater. 11, 455467.

Skovrup, M.J., 2005. SecCool API. IPU-Refrigeration and Energy Engineering <http://www.ipu.dk/Indhold/koele-og-energiteknik/Seccool.aspx> (accessed 13/07/2016).

SP, 2015. Solar Keymark Certificate HTHEATstore 35/08. Borås (Sweden) < http://www.solarkeymark.dk> (accessed 13/07/2016).

Sun, T., Teja, A.S., 2004. Density, viscosity and thermal conductivity of aqueous solutions of propylene glycol, dipropylene glycol, and tripropylene glycol between $290 \mathrm{~K}$ and 460 K. J. Chem. Eng. Data 49, 1311-1317. doi:10.1021/je049960h

Trier, D., 2016. Personal communication with D. Trier (PlanEnergi).

Tsierkezos, N.G., Palaiologou, M.M., 2009. Ultrasonic studies of liquid mixtures of either water or dimethylsulfoxide with ethylene glycol, diethylene glycol, triethylene glycol, tetraethylene glycol, 1,2propylene glycol and 1,4-butylene glycol at 298.15 K. Phys. Chem. Liq. 47, 447-459. doi:10.1080/00319100802104855

VDI, 2004. VDI-Richtlinie: VDI 6002 Blatt 1 Solare Trinkwassererwärmung - Allgemeine Grundlagen Systemtechnik und Anwendung im Wohnungsbau.

Wang, X.A., Wu, L.G., 1990. Analysis and performance of flat-plate solar collector arrays. Sol. Energy 45, 71-78.

Weitbrecht, V., Lehmann, D., Richter, A., 2002. Flow distribution in solar collectors with laminar flow conditions. Sol. Energy 73, 433-441.

Windeleff, J., Nielsen, J.E., 2014. Solar District Heating in Denmark. Danish Energy Agency and PlanEnergi. 